\title{
1 Cryptic haplotypes of "Candidatus Liberibacter africanus"
}

3 Warrick R Nelson, The New Zealand Institute for Plant \& Food Research Limited, Private Bag 4704,

4 Christchurch 8140, New Zealand

5 Sandrine Eveillard, Marie-Pierre Dubrana and Joseph M Bové, Université Bordeaux and INRA, UMR

61332 Biologie du fruit et Pathologie, 71, Ave. Edouard Bourlaux, 33883 Villenave d'Ornon, France

7 Dedicated to the memory of Colette Bové-Dumeau (1927-2014).

Abstract

"Candidatus Liberibacter africanus" (Laf) has long been recognised as a causal agent of the devastating citrus disease huanglongbing (HLB) or citrus greening. This species is currently restricted to Africa, the Arabian Peninsula and some Indian Ocean islands and vectored by the African citrus psyllid, Trioza erytreae. Blotchy mottle on citrus leaves is characteristic of the disease.

Somewhat similar symptoms in the Rutaceous tree Calodendrum capensis (Cape Chestnut) resulted in the discovery of Laf outside commercial citrus crops in South Africa. This was classed as a subspecies of Laf (capensis, hence LafC). In subsequent surveys of both commercial citrus crops and Calodendrum, both natural and ornamental specimens, LafC was not found in the citrus crop, nor has Laf been found in C. capensis. HLB was reported from Madagascar in 1968 but no sequences from this source have so far been published.

Until fairly recently, only the reference 16 S rRNA gene sequences of Laf (L22533) and LafC (AF137368) had been deposited in GenBank. Both of these reference sequences contain a number of unresolved nucleotides. Resolving these nucleotide positions by aligning against more recently available sequences, it becomes evident that these unresolved positions represent one percentage point difference in similarity between Laf and LafC. The originally reported $97.4 \%$ similarity is therefore incorrect based on this new information. Recalculating the similarity on the full length $16 \mathrm{~S}$ rDNA sequence results in $99.54 \%$ similarity, a value too high to justify a subspecies status. LafC should therefore be reduced to that of a haplotype of Laf.

Further, the six $16 \mathrm{~S}$ rRNA gene sequences currently available in GenBank identified as the species Laf separate into 2 haplotype groups. The 3 haplotypes of Laf are therefore LafA designated as the first accession sequenced (L22533), LafC for the former capensis subspecies and to recognise the prior use of this term, and LafB for the third haplotype not previously recognised. Thus the cryptic presence of 3 haplotypes is revealed by this review of the Laf $16 \mathrm{~S}$ rDNA sequences. 
Huanglongbing (HLB), also known as citrus greening, is a serious disease threatening the economic existence of many commercial citrus orchards. It has recently spread to the major production regions of Brazil, Florida and California (Wang \& Trivedi, 2013). Currently, 3 species of "Candidatus Liberibacter", named for the continent of first discovery, are associated with symptomatic commercial citrus plants (Bové, 2006), "Candidatus Liberibacter asiaticus" (Las) being the most geographically widespread (Bové, 2014).

"Candidatus Liberibacter africanus" (Laf) is associated with HLB throughout East Africa, the Arabian Peninsula and Indian Ocean islands (Bové, 2006; Bové, 2014), including Madagascar (Bové \& Cassin, 1968). The Rutaceous tree, Calodendrum capense (Cape Chestnut) has also been discovered to be infected by "Ca. Liberibacter africanus subsp. capensis" (LafC)(Garnier et al., 2000). This has subsequently been found to be widespread in South Africa where this tree is both native and grown ornamentally (Phahladira et al., 2012). In spite of the subspecies being widespread, only Laf is present in symptomatic commercial citrus orchards in South Africa (Pietersen et al., 2010). Other native Rutaceae species in South Africa also tested positive for Laf and LafC and possibly another variant of the species, but interpreted as a series of subspecies of Laf (Roberts et al., 2014).

The original description of LafC was based on three gene fragments (Garnier et al., 2000), of which the 16S rRNA gene is taxonomically the most important (Weisburg et al., 1991; Woese \& Fox, 1977). This 16 S sequence (GenBank accession AF137368) was noted as having $97.4 \%$ similarity with Laf (L22533). Three percent divergence over the full gene sequence is a commonly recognised requirement for bacterial species designation (Stackebrandt \& Goebel, 1994), thus the subspecies status for LafC. Closer inspection of these sequences revealed 6 unresolved nucleotides on LafC and 5 in the Laf reference sequences. There is thus potentially one percentage point of difference derived simply from these unresolved nucleotide positions. A review of this subspecies status is now feasible with the availability of more recent accession sequences.

\section{Methods and Materials}

A literature review revealed further examples of both Laf and LafC $16 \mathrm{~S}$ rDNA sequences, as well as some sequences for 16S-23S ISR, 23S and 50S rRNA gene regions. The megablast protocol in GenBank was used to find further closely related sequences.

These sequences were downloaded from the NCBI database (GenBank) and aligned in ClustalX 2.1 (Larkin et al., 2007). Sequences for 165 rDNA from the genomes of two other Liberibacter species ("Ca. L. asiaticus" and "Ca. L. solanacearum", Las and Lso respectively) were also downloaded for additional comparison. These were chosen as phylogenies generally place them closest to Laf (Nelson et al., 2013).

DNA material stored from symptomatic leaves of sweet orange collected in Madagascar during 2011, previously reported to be Laf by PCR (Bové, 2014), was retested using the primer pair OA1/Oi2c (Jagouiex et al., 1996) and the resultant $16 \mathrm{~S}$ rDNA samples sequenced. The rplJ component of the $50 S$ rRNA gene was also sequenced. 


\section{5}

76

77

78

79

80

81

82

83

84

\section{Results}

On the $16 \mathrm{~S}$ rRNA gene, 15 sequences identified as Laf or LafC were found. Three of these proved to contain only a very short component of the $16 \mathrm{~S}$ gene and were discarded. Aligning the remaining 12 sequences showed a number of apparently random SNPs scattered across the accessions, presumably arising as sequencing errors, but the LafC sequences separated clearly.

In the sequence L22533 (Laf), there are 5 nucleotide positions labelled " $N$ ". From within the aligned set of sequences, these can be unambiguously resolved to the nucleotides $T, C, G, A$ and $G$. Similarly, in the sequence AF137368 (LafC), these also resolve unambiguously to $A, A, A, G, C, C$. Laf sequences also aligned into 2 groups over 7 SNPs (Table 1), here designated as haplotypes LafA and LAfB. Excluding the occasional single sequence SNPS, the number of SNPS separating the 2 haplotypes and subspecies is outlined in Table 2. Although the sequence of each accession varied in length, these SNPs occur over an approximately $1100 \mathrm{bp}$ length. Aligning the Laf sequences against the full 165 gene sequences for Las and Lso indicated that all the SNPs in Table 1 occur within the overlapping regions. Liberibacter $16 \mathrm{~S}$ genes are approximately $1500 \mathrm{bp}$ (Nelson et al., 2015). Until full Laf sequences are available, the similarities reported here might prove to be high if further SNPS exist in the currently unknown regions. There are 8 SNPs between Las and Lso in these end regions of the gene, representing $0.53 \%$ difference. Assuming a similar number of SNPs between the Laf sequences in these end regions, we can calculate a likely worst-case scenario for the number of SNPS between the proposed haplotypes and the percentage similarity, assuming a 16S rRNA gene length of $1500 \mathrm{bp}$.

Only 4 sequences across the 16S-23S ISR and 23S partial gene regions were found in GenBank (LAU61360, EU754741, FJ914622, JF819884, JF819885) for Laf and none for LafC. The LafC sequence has been mentioned as being closer to Las than Laf, because only one tRNA (alanine) is present in the ISR of Laf, while two tRNAs (alanine and isoleucine) occur in the ISR of Las and LafC (Garnier et al., 2000).

Over a common segment of $479 \mathrm{bp}$ on the $50 \mathrm{~S}$ gene region ( $\beta$-operon) there are 68 SNPs between Laf and LafC (14 and 4 accessions respectively)(Phahladira et al., 2012; Pietersen et al., 2010). The available sequence material in the $50 \mathrm{~S}$ gene confirms the basic Laf/LafC separation, but we feel that separating LafA and LafB is as yet inconclusive with only 2 SNPs across the 4 accessions.

The $16 \mathrm{~S}$ sequences derived from Madagascar material aligned with Laf $A$ and the $\mathrm{rplJ}$ sequence (GenBank) aligned with EF122255, a sequence with metadata indicating it is derived from commercial citrus material in South Africa. 
bioRxiv preprint doi: https://doi.org/10.1101/016410; this version posted March 12, 2015. The copyright holder for this preprint (which was not certified by peer review) is the author/funder, who has granted bioRxiv a license to display the preprint in perpetuity. It is made available under aCC-BY-ND 4.0 International license.

Table 1 Proposed haplotypes and SNP differences on the 16S rRNA gene within "Candidatus Liberibacter africanus" (Laf) sequences. The nucleotide numbers count from the beginning of the reference sequence L22533 although the alignment was done using a 1057 bp length common to all sequences. Shaded SNPs are positions of ambiguity between the sequences within a series where the SNP is in the same position as the nucleotide in one of the other haplotypes.

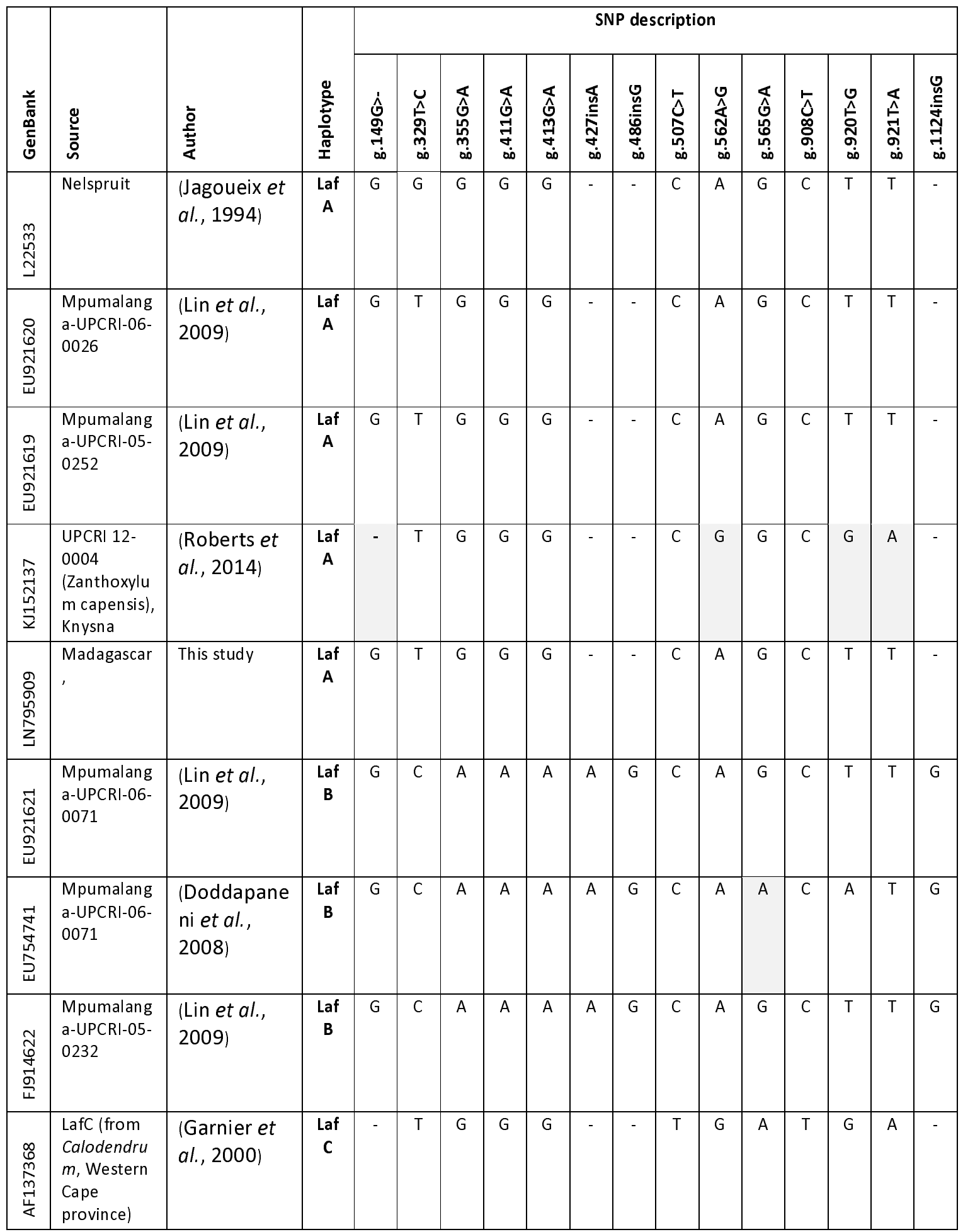


bioRxiv preprint doi: https://doi.org/10.1101/016410; this version posted March 12, 2015. The copyright holder for this preprint (which was not certified by peer review) is the author/funder, who has granted bioRxiv a license to display the preprint in perpetuity. It is made available under aCC-BY-ND 4.0 International license.

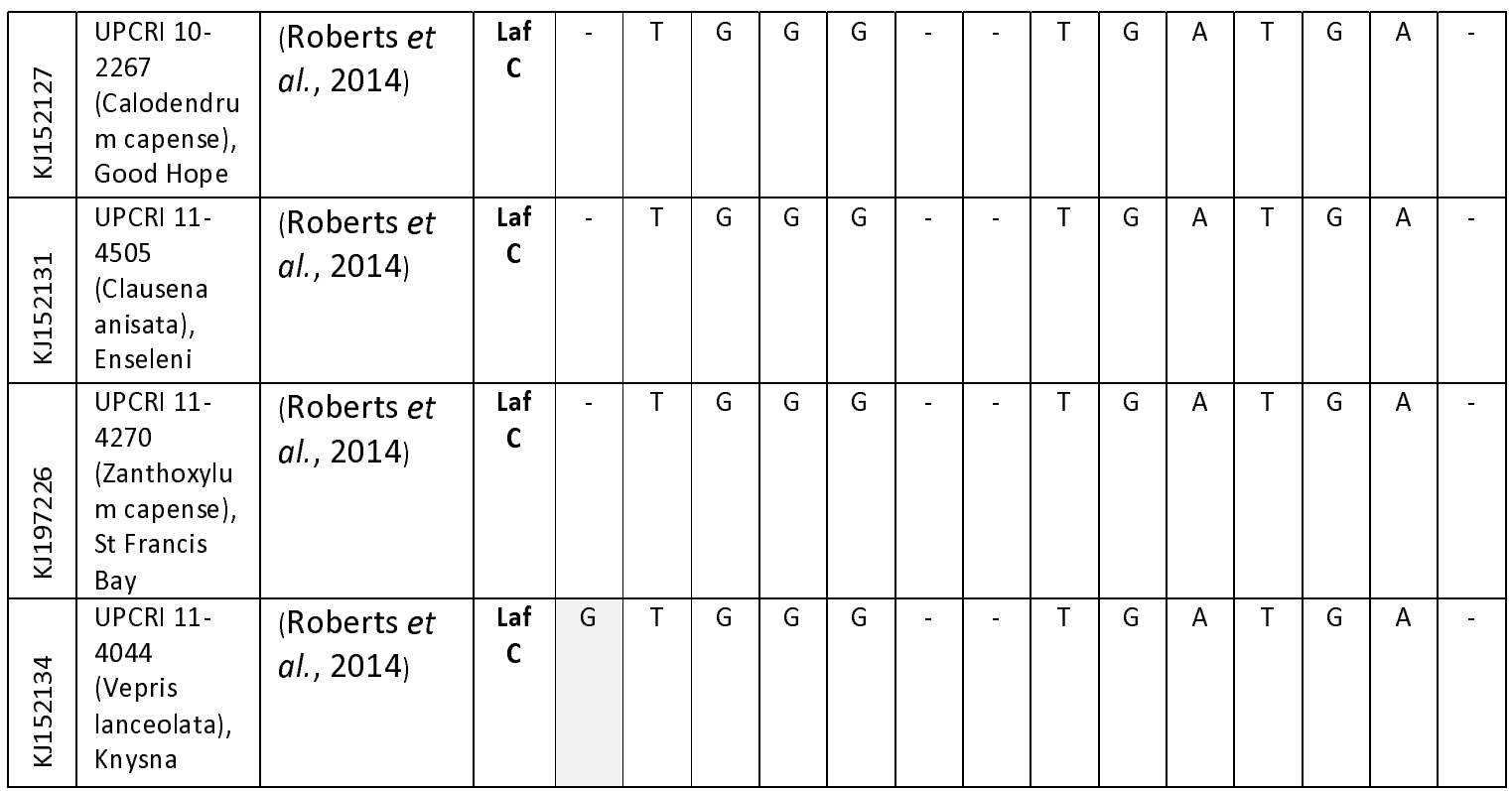

113

Table 2 Percent identity similarity between "Candidatus Liberibacter africanus" (Laf) haplotypes based on 16S rRNA gene sequences, \% similarity calculated on a $1500 \mathrm{bp}$ length. An alternate \% similarity figure is indicated in parentheses assuming a further 8 SNPs exists in the currently unknown segments of the gene.

\begin{tabular}{|l|l|l|}
\hline Comparison identity & SNPs & \% similarity \\
\hline LafA:LafB & $7(15)$ & $99.53(99.0)$ \\
\hline LafA:LafC & $7(15)$ & $99.53(99.0)$ \\
\hline LafB:LafC & $14(22)$ & $99.07(98.54)$ \\
\hline
\end{tabular}

\section{Discussion}

120 The unresolved nucleotides in the sequences for Laf and LafC ( 11 positions in total) are readily resolved to their correct nucleotide by comparison against the other 10 sequences now available in GenBank. These newly resolved positions represent one percentage point of similarity between Laf and LafC, thus the originally described $97.4 \%$ (Garnier et al., 2000) similarity becomes $98.4 \%$. However, this similarity calculation was conducted on the known sequence proportion of the gene since at the time the full length of the gene was not known. Although the full $16 \mathrm{~S}$ gene sequence for Laf is still not available, it is likely to be approximately $1500 \mathrm{bp}$ in length as found in 4 other species of Liberibacter (Nelson et al., 2015). Across the sequences currently available, only approximately 40 bases at the beginning and 30 at the end of the gene sequence remain unknown, thus allowing a closer estimate of similarity between the species and the subspecies (Table 2).

Variation across the $16 \mathrm{~S}$ rRNA gene appears to be quite large with 14 SNPS apparent across the Laf/LafC accessions available, 7 of them between LafA/LafB and a different 7 between LafA/LafC, with all 14 being different between LafB/LafC. For comparison, Las appears to be homogenous across accessions on the 16S rRNA gene (Moreno-Enríquez et al., 2014; Nelson, 2012), while for Lso al., 2011; Nelson et al., 2013; Teresani et al., 2014). 
136

137

138

139

140

141

142

143

144

145

146

147

148

149

150

151

152

153

154

155

156

157

158

159

160

161

162

163

164

165

166

167

168

169

170

171

172

173

174

175
The unexpected separation into 2 groups on the 16S rRNA gene within the currently known Laf species suggests 2 haplotypes, here designated LafA and LafB (Table 2). No prior study has indicated that there were genetic differences within Laf on commercial citrus. This suggests 3 haplotypes within the Laf species, 2 primarily indicated by sequences derived from commercial citrus crops, and the previous subspecies designation "capensis" can be resolved to a haplotype but retaining the short form of LafC. Caution is required in this conclusion since the LafB designation is based on only 3 available sequences and 2 of these, although sequenced by different laboratories, are clearly derived from the same field sample. The metadata associated with these sequences give little indication of geographical or plant/insect host separation. For LafA/LafB they are primarily from commercial citrus crops and LafC from native Rutaceous species. This provides a stark contrast to the analogous situation in Lso where the haplotypes also express partial plant/insect host and geographic separation (Nelson et al., 2011; Nelson et al., 2013; Teresani et al., 2014). If the A/B haplotypes can be confirmed, they indicate 2 separate pathosystem events from the respective currently unknown African native plant hosts into commercial citrus, since Citrus is not native to Africa (Beattie et al., 2008), and LafC has yet to make this jump as it is not yet known from citrus (Phahladira et al., 2012).

The 50S rRNA gene sequences show clear separation between Laf and LafC as expected, with only a suggestion on 4 of 15 Laf sequences showing SNPs. Caution is suggested in considering this indicative of LafA/B haplotypes as these SNPs occur together and only 4 bases from the end of the sequence. Further, there is no indication from the metadata to tie these 4 sequences together with the 3 suggested as LafB from the $16 \mathrm{~S}$ gene.

Although previously known that Laf was the species responsible for HLB on Madagascar by both epidemiological and PCR studies (Bové \& Cassin, 1968; Bové, 2014), this study confirms not only the species as Laf via both $16 \mathrm{~S}$ and rplJ genes, but that it is also haplotype LafA. This very strongly suggests an incursion event of LafA from Africa to Madagascar, rather than a Gondwanan origin, in spite of the position of Madagascar in Gondwana between East Africa and India.

The very recent suggestion of a further three subspecies of Laf (Roberts et al., 2014) can be resolved within this proposal of haplotypes rather than subspecies within Laf by giving them a biotype designation, recognising the current host plant differences. Laf subspecies vepridis is a biotype of LafA, while Laf subspecies zanthoxyli and Laf subspecies clausenae are biotypes of LafC.

\section{Conclusion}

Instead of the species Laf and subspecies capensis, re-analysis of the phylogenetically important $16 \mathrm{~S}$ rRNA gene suggests the subspecies is not that far removed from the species and should be revised to haplotype status. Further, existing sequences of Laf indicate that this species also comprises two haplotypes. Therefore two haplotypes (LafA and LafB) are known symptomatically in commercial citrus orchards while the third ( $\mathrm{LafC}$ ) is known only from very mild symptoms in native Rutaceous plants but not (yet) in citrus. Thus the cryptic presence of three haplotypes is revealed by this review of the Laf 165 rDNA sequences. 
176

177

178

179

180

181

\section{References}

Beattie, G., Holford, P., Mabberley, D., Haigh, A. \& Broadbent, P. (2008). On the origins of CitruS, Huanglongbing, Diaphorina citri and Trioza erytreae. International Research Conference on Huanglongbing, Orlando, Florida , 25-57.

Bové, J. M. (2006). Huanglongbing: a destructive, newly-emerging, century-old disease of citrus. Journal of Plant Pathology 88, 7-37.

Bové, J. M. (2014). Heat-tolerant Asian HLB meets Heat-sensitive African HLB on the Arabian Peninsula. Why?. Journal of Citrus Pathology 1, 1-78.

Bové, J. M. \& Cassin, J. P. (1968). Problèmes de l'agrumiculture malgache; compterendu de mission. Document IRFA: $52 \mathrm{p}$.

Doddapaneni, H., Liao, H., Lin, H., Bai, X., Zhao, X., Civerolo, E., Irey, M., Coletta-Filho, H. \& Pietersen, G. (2008). Comparative phylogenomics and multi-gene cluster analyses of the Citrus Huanglongbing (HLB)-associated bacterium Candidatus Liberibacter. BMC Res Notes 1, 72.

Garnier, M., Jagoueix-Eveillard, S., Cronje, P., Le Roux, H. \& Bové, J. (2000). Genomic characterization of a liberibacter present in an ornamental rutaceous tree, Calodendrum capense, in the Western Cape province of South Africa. Proposal of "Candidatus Liberibacter africanus subsp. capensis". Int J Syst Evol Microbiol 50, 2119-2125.

Jagoueix, S., Bové, J. M. \& Garnier, M. (1994). The phloem-limited bacterium of greening disease of citrus is a member of the $\alpha$-subdivision of the Proteobacteria. Int J Syst Bacteriol 44, 379-386.

Jagouiex, S., Bové, J. M. \& Garnier, M. (1996). PCR detection of the two "Candidatus" liberobacter species associated with greening disease of citrus. Mol Cell Probes 10, 43-50.

Larkin, M. A., Blackshields, G., Brown, N. P., Chenna, R., McGettigan, P. A., McWilliam, H., Valentin, F., Wallace, I. M., Wilm, A. \& other authors (2007). Clustal W and Clustal X version 2.0. Bioinformatics 23, 2947-2948.

Lin, H., Doddapaneni, H., Munyaneza, J. E., Civerolo, E. L., Sengoda, V. G., Buchman, J. L. \& Stenger, D. C. (2009). Molecular characterization and phylogenetic analysis of 165 rRNA from a new species of "Candidatus Liberibacter" associated with Zebra chip disease of potato (Solanum tuberosum L.) and the potato psyllid (Bactericera cockerelli Sulc). Journal of Plant Pathology 91, 215-219.

\section{Moreno-Enríquez, A., Minero-García, Y., Ramírez-Prado, J. H., Loeza-Kuk, E., Uc-Varguez, A. \&} Moreno-Valenzuela, O. A. (2014). Comparative analysis of $16 \mathrm{~S}$ ribosomal RNA of 'Candidatus Liberibacter asiaticus' associated with Huanglongbing disease of Persian lime and Mexican lime reveals a major haplotype with worldwide distribution. African Journal of Microbiology Research 8, 2861-2873.

Nelson, W. (2012). First record of Trioza vitreoradiata (Maskell)(Hemiptera: Triozidae) in citrus. Citrus Research \& Technology 33, 35-38. 

aCC-BY-ND 4.0 International license.

211 Nelson, W. R., Fisher, T. W. \& Munyaneza, J. E. (2011). Haplotypes of "Candidatus Liberibacter

212 solanacearum" suggest long-standing separation. European Journal of Plant Pathology 130, 5-12.

213 Nelson, W. R., Munyaneza, J. E., McCue, K. F. \& Bové, J. M. (2013). The Pangaean origin of

214 "Candidatus Liberibacter" species. Journal of Plant Pathology 95, 455-461.

215 Nelson, W. R., Wulff, N. A. \& Bové, J. M. (2015). Intragenomic homogeneity on Liberibacter $16 \mathrm{~S}$

216 rDNA confirms phylogeny and explains ecological strategy. bioRxiv doi:

217 http://dx.doi.org/10.1101/016188.

218 Nelson, W., Sengoda, V., Alfaro-Fernandez, A., Font, M., Crosslin, J. \& Munyaneza, J. (2013). A new

219 haplotype of "Candidatus Liberibacter solanacearum" identified in the Mediterranean region.

220 European Journal of Plant Pathology 135, 633-639.

221 Phahladira, M., Viljoen, R. \& Pietersen, G. (2012). Widespread occurrence of "Candidatus

222 liberibacter africanus subspecies capensis" in Calodendrum capense in South Africa. European

223 Journal of Plant Pathology 134, 39-47.

224 Pietersen, G., Arrebola, E., Breytenbach, J., Korsten, L., le Roux, H., la Grange, H., Lopes, S., Meyer,

225 J., Pretorius, M. \& other authors (2010). A survey for 'Candidatus Liberibacter' species in South

226 Africa confirms the presence of only ' $C a$. L. africanus' in commercial citrus. Plant Dis 94, 244-249.

227 Roberts, R., Steenkamp, E. T. \& Pietersen, G. (2014). Novel lineages of 'Candidatus Liberibacter

228 africanus' associated with native Rutaceae hosts of Trioza erytreae in South Africa. Int I Syst Evol

229 Microbiol, doi:10.1099/ijs.0.069864-0.

230 Stackebrandt, E. A. \& Goebel, B. M. (1994). Taxonomic note: a place for DNA-DNA reassociation 231 and $16 \mathrm{~S}$ rRNA sequence analysis in the present species definition in bacteriology. Int J Syst Bacteriol $232 \quad 44,846-849$.

233 Teresani, G. R., Bertolini, E., Alfaro-Fernandez, A., Martínez, C., Tanaka, F. A. O., Kitajima, E., 234 Rosello, M., Sanjuan, S., Ferrandiz, J. C. \& other authors (2014). Association of 'Candidatus

235 Liberibacter solanacearum' with a vegetative disorder of celery in Spain and development of a real-

236 time PCR method for its detection. Phytopathology 104, 804-811.

237 Wang, N. \& Trivedi, P. (2013). Citrus Huanglongbing: a newly relevant disease presents

238 unprecedented challenges. Phytopathology 103, 652-665.

239 Weisburg, W., Barns, S., Pelletier, D. \& Lane, D. (1991). 16S ribosomal DNA amplification for 240 phylogenetic study. J Bacteriol 173, 697-703.

241 Woese, C. \& Fox, G. (1977). Phylogenetic structure of the prokaryotic domain: The primary

242 kingdoms. Proceedings of the National Academy of Sciences 74, 5088-5090. 